\title{
FETR: a framework to establish trust relationships among organizations in VBEs
}

\author{
Simon Samwel Msanjila • Hamideh Afsarmanesh
}

Received: 2 September 2008 / Accepted: 2 September 2008 / Published online: 13 November 2008

(C) The Author(s) 2008. This article is published with open access at Springerlink.com

\begin{abstract}
Organizations compete in acquiring competitive resources, knowledge, and competencies. In the past, organizations applied the acquired resources, knowledge and competencies to gain superiority and thus outperform others in getting customers and brokering opportunities. In this manner, the superior organizations forced the inferior organizations outside the market. However, in the current market, when an opportunity is brokered, organizations need to collaborate, more than competing, by sharing the acquired resources, knowledge, and competencies to respond to the opportunity which none of them could handle otherwise. This means organizational strategies must now adapt to the notion of collaboration with others. One important organizational strategy necessary in virtual organizations breeding environments (VBE) is focused on the organizational preparedness that is required to enhance chances of participating in virtual organizations (VOs). A crucial aspect of preparedness is the establishment of trust relationships with other member organizations to smoothen the sharing of resources, knowledge, and competence, and in turn facilitate the organizations' collaboration. In this paper we present the FETR: A Framework to Establish Trust Relationships among organizations in VBEs. We also present and analyze risks that can emerge and thus hamper the established relationships among organizations. We also present the promotion of trust relationships among organizations.
\end{abstract}

Keywords Inter-organizational trust - Trust relationship between organizations - Rational trust analysis - Trust

S. S. Msanjila $(\varangle) \cdot$ H. Afsarmanesh

University of Amsterdam, Amsterdam, The Netherlands

e-mail: msanjila@science.uva.nl

H. Afsarmanesh

e-mail: hamideh@science.uva.nl
Management system - Virtual organizations breeding environments · Virtual organization

\section{Introduction}

There is no consensus yet in the literature on the definition of trust and what constitutes the management of trust among different entities. Researchers have recognized its importance in smoothing interactions and co-working among individuals as well as organizations. They have differently perceived trust and applied for dissimilar purposes which in turn have made it difficult to achieve common understanding among them.

The word "trust" as used daily by individuals refers to the opinion of somebody about another. It does not only reflect an estimation of another's intention but also of the competencies, namely capabilities, capacities, etc. of others that are typically considered in order to establish trust relationships with other people. Gambetta (1988) provided a definition of trust, which has been widely used, "as the subjective probability by which an individual " $A$ " expects another individual " $B$ " to perform a given action on which A's welfare depends".

This paper addresses inter-organizational trust in VBEs as an enabler for efficiently managing it as well as creating VOs constituting its members as potential partners. In this paper we apply the following definitions of VO and VBE.

A $\mathbf{V O}$ is an association of (legally) independent organizations (VO partners) that come together and share resources and skills to achieve a common goal, such as acquiring and executing a market/society opportunity (Camarinha-Matos and Afsarmanesh 2006).

A $\boldsymbol{V B E}$ is defined as an alliance of organizations (VBE members) and related supporting institutions, adhering 
to a base long term cooperation agreement, and adopting common operating principles and infrastructures, with the main goal of increasing both their chances and preparedness towards collaboration in potential VOs (Afsarmanesh and Camarinha-Matos 2005).

In VBE environments, the subject of trust relationships shall be addressed considering organizations as the smallest unit and not the people, and specifically addressing three kinds of organizations, including: the VBE member organizations, the external stakeholder organizations, and the VBE administration organization. Therefore, while this work can benefit from the general past research on trust relationships among individuals, their results cannot be directly applied here (Msanjila and Afsarmanesh 2007d).

Trust among organizations in VBEs is a complex subject, which must be addressed considering "its interdisciplinarity of areas as well as the heterogeneity and contradictions of interests and goals" among the involved organizations (Msanjila and Afsarmanesh 2007b). In our research on trust the identification and tuning of trust elements, the modeling of trust relationships, the assessment of trust level, and the establishment and promotion of trust relationship constitute the main focus on the management of trust among organizations in VBEs (Msanjila and Afsarmanesh 2007d). These specific topics are addressed regarding the establishment of trust relationships: (1) among the VBE member organizations, (2) between the VBE member organizations and the VBE administration organization, and (3) between the external organizations and the VBE. In Msanjila and Afsarmanesh (2007c) we addressed the identification of trust elements for organizations, in Msanjila and Afsarmanesh (2007b) we addressed the modeling of trust relationships among organizations, and in Msanjila and Afsarmanesh (2007a) we addressed the assessment of trust level of organizations. This paper proposes the FETR framework for guiding the establishment of trust relationships among organizations in VBEs.

Problem area and research domain

Trust is defined differently in different disciplines and research. Among others, the three following definitions are dominant:

- Trust is the willingness of a trustor to be vulnerable to the actions of another party based on the expectations that the trustee will perform a particular action important to the trustor irrespective of the ability to monitor or control the trustee (Mayer et al. 1995).

- Trust is the belief in the competency of an entity to act dependably, securely and reliably within a specified context (Grandison and Sloman 2000).
- Trust is a psychological condition comprising the trustor's intention to accept vulnerability based upon expectation of trustee's intentions and behavior (Rousseau et al. 1998).

The diversity among these definitions makes it difficult to properly characterize trust and its concepts. There are many theories on trust, some of which diverge from each other only in their identification of the grounds on which they are based (Rousseau et al. 1998). Despite the difficulties in solidifying the definition of trust, in practice, trust is a base for collaboration among individuals as well as among organizations. Research addressing the subject of collaboration among organizations had reported that the effectiveness of VBE operation depends on the right balance of trust level among organizations (Msanjila and Afsarmanesh 2007b).

Traditionally, trust has been practiced and applied as a subjective phenomenon and thus its evaluation has been opinionbased. However, trust among organizations is the base for any collaborative transaction in which they get involved. Thus specifically for SMEs (Small and Medium Enterprises), their survivability may depend on getting involved in such collaborations. Traditionally, trust among organizations was only established "bi-laterally" and subjectively based on reputation and recommendation from others. In large networks such as VBEs however, applying traditional approaches for creating bilateral trust among organizations in VBEs is difficult, mostly due to the following reasons:

- It is hardly feasible for a trustor organization to collect reputation data or peers' opinions about the trustworthiness of a trustee organization, with whom it had never interacted before.

- It is hardly feasible to (rationally) reason on the trustworthiness of organizations based on subjective data.

Therefore, subjective trust (opinion-based) is too risky and rational trust (fact-based) is required to be created among organizations to facilitate goal oriented collaborations. To support the creation of trust among organizations, a rational (fact-based) approach proposed in our previous work (Msanjila and Afsarmanesh 2007a, c) is adopted in this paper. In this approach, we suggest applying formal mechanisms to assess the trust level of organizations. These mechanisms are formulated applying trust criteria for organizations taking into consideration the need of rational data, such as the past performance, the achieved results, etc. With this approach an organization can trust others rationally and based on facts about their trust level. Therefore, trust level of organizations is properly assessed through their trust criteria and can be supported by some rational reasoning based on the mathematical equations. With this approach the VBE administrator 
can assess the trust level of trustee organizations and provide it to the trustor organization when requested. In this paper we apply the following definition of trust among organizations.

Trust among organizations, as it is applied in VBEs, is defined as the objective-specific confidence of a trustor to a trustee based on the results of fact-based assessment of trust level of the trustee (Msanjila and Afsarmanesh 2007c).

Therefore, objective based trust creation refers to the process of creating trust among organizations based on the results of the fact-based assessment of their trust levels. Only measurable or numeric data are applied to the assessment and the resulted trust levels can be supported with some formal reasoning applied during the assessment of trust level, which in turn enhances the reasoning of the established trust relationships (Msanjila and Afsarmanesh 2007a).

The remaining part of this paper is organized as follows: Section "Antecedents and importance of trust in VBEs" provides the definitions of base concepts. Section "Definitions of main concepts" describes the problem area and presents research questions. Section "Research Questions" addresses the antecedents and importance of trust. Section "Establishing trust relationships" addresses the establishment of trust relationships among organizations. Section "Types of validity evidences for trust-related data" addresses the importance of validity of information. Section "Promoting trust relationships among organizations" presents proposed approaches for promoting trust relationships in the VBE. Section "Risks in VBEs versus trust relationships between organizations" discusses the tradeoffs between risks in the VBE and trust relationships among the member organizations. Section "Conclusion" concludes the paper.

\section{Antecedents and importance of trust in VBEs}

In this section we address the antecedents and importance of trust relationships among organizations in VBEs. We first address the antecedents.

Antecedents of establishing trust relationships among organizations

Trust antecedents are cardinal elements that may have a positive or negative impact on the effectiveness of the established trust relationships among organizations. Three trust antecedents are identified for organizations in this article, namely shared values, previous interactions, and practiced behaviors.

Shared values occur when the trustor organization and the trustee organization have a common understanding on important issues that might influence the creation of trust towards each other, such as missions, goals, policies and interpretations of right or wrong (Morgan and Hunt 1994). Shared values can range from business objectives to internal management processes and approaches. In business environments, it is more difficult to have shared values between two competing organizations than between two organizations that are complementing each other (Cosimano 2004). Typically, when two organizations have a common understanding they both feel secure in the knowledge that there will be no unexpected results during the cooperation/collaboration. It is therefore easier to establish a trust relationship under such conditions. As an aspect of preparedness, the VBE must ensure that member organizations have a certain amount of shared values.

Previous (fruitful) interactions between the trustor organization and the trustee organization-either directly or indirectly (through other intermediate organizations) — enhance the effectiveness of the established trust relationships. The interactions can be formal as well as informal, such as the formal exchange of meaningful information or the informal acquisition of updates. Interactions can also involve individuals who work within the two organizations. Even though there may be no existing business interactions, the existence of previous interactions will enable the establishment of the trust relationship to be smoothened.

Practiced (moral and/or ethical) behaviours basically refer to the opposition of opportunistic behaviour. Opportunistic behaviour means taking immediate advantage —often unethically — of any circumstance that may generate possible benefit. Opportunistic behaviour in competitive markets seems natural because the focus of organizations in such environments is on the acquisition of customers, without regard for long-term relationships with other organizations. In collaborative networks, however, organizations must cooperate in order to serve the same customers. Opportunistic behaviour has a negative impact on the effectiveness of trust relationships. It derives from transaction cost literature and is defined as self-interest seeking with guile (Mukherjee 2003). Here we refer to opportunistic behaviour as ungentle action taken by VBE member organizations for the purpose of benefiting themselves unethically more than others (e.g. quitting the collaboration once they have made a gain, or when they expect the risks of the collaboration to be a threat).

Importance of establishing trust relationships among organizations

The stability of a VBE requires a delicate balance of levels of trust in various specific trust relationships between the organizations involved. VBEs are characterized as multiactor environments, in which each actor has autonomy, interests, and goals that might contradict those of others. The interdisciplinary and heterogeneity nature of several aspects, 
such as business domains and technologies, are some issues that increase the complexity of creating trust between organizations in VBEs. A catalyser for the enhancement of cooperation between member organizations in VBEs is the establishment of trust relationships, which is why past research states that trust is the most salient factor for cooperation networks in achieving network objectives (Morgan and Hunt 1994). Trust relationships between organizations are more important for industry-based VBEs that operate under pressure from the global economy, the increasing value of information, and the mounting uncertainties surrounding their businesses. Several advantages can be gained once trust relationships between member organizations have been properly established and managed in the VBE. A number of these are mentioned below.

$\diamond \quad$ Motivating member organizations to accept responsibilities in case of uncertain or incomplete information.

$\diamond \quad$ Facilitating the achievement of common goals by encouraging information exchange, knowledge sharing, tools sharing, and so forth, between member organizations.

$\diamond \quad$ Encouraging member organizations to avoid opportunistic behaviour during collaboration.

$\diamond \quad$ Easing the process of creating and launching VOs by smoothing the partner selection processes.

$\diamond \quad$ Accelerating the contract negotiation process between selected VO partners.

$\diamond$ Creating a competitive advantage by facilitating the reduction of governance internalization (acquisitions), and transaction costs.

$\diamond \quad$ Enabling open communication and reducing conflicts.

\section{Definitions of main concepts}

This section presents the definitions of the base concepts applied in this paper as follows.

Trust actors: Refer to the two organization parties involved in a specific trust relationship. The first party is the organization that needs to assess the trustworthiness of another and is referred to as the trustor. The second party is the organization that needs to be trusted, and thus its trust level will be assessed and is referred to as the trustee.

Trust elements: Refers to the hierarchical-related elements from abstract (non measurable) ones which represent the root node to the measurable ones which represent lowest child nodes that together characterize both trust and trust relationships, and form the base for deciding about the data needed for the assessment of trust level of organizations. Trust elements hierarchically include: trust objectives, trust perspectives, trust requirements and trust criteria.

Trust objective: Refers to the purpose for which the trust relationship establishment among the involved organizations is required. Examples of trust objectives include the following: for inviting an organization to join a $\mathrm{VO}$, for appointing or selecting an organization as the VO coordinator, etc.

Trust perspective: Represents the specific "point of view" of the trustor on the main aspects that must be considered for assessing the trust level of the trustee. In Msanjila and Afsarmanesh (2007c) we presented five general trust perspectives for organizations namely: Technological perspective, Social perspective, Managerial perspective, Economical perspective, and Structural perspective.

Trust requirement: Represents the essentials (cardinals) that characterize and guide on how the respective trust perspective can be realized. Thus, trust requirements are the fundamental cardinals that guide or suggest what must be met in order for the respective trust perspective to be realized. For instance, "financial stability" is an example requirement that must be met to support the economical perspective; similarly "compliance with community standards" is a requirement for the social perspective, etc.

Trust criteria: represent the measurable trust elements that characterize a respective trust requirement. Therefore, for each organization, the values of its trust criteria (related to a requirement) can be used to make a rational (fact-based) judgment on whether the respective requirement is met. Each trust criteria constitutes a value structure that defines the acceptable structure for its data, such as scalars, vectors, arrays, list of strings, etc. Furthermore, the value structure defines the metric that is applied to scale the specified data. The only source of data for trust criteria is the respective trustee organization. Therefore in each VBE, member organizations shall submit data related to their trust criteria, and keep them up-to-date. Data related to trust criteria of organizations will be used in the VBE for different purposes related to trust management. However, access to these data is limited only to the VBE administration. A list of trust criteria identified in our research is presented in Msanjila and Afsarmanesh (2007c).

Known factors: represent a set of domain/application dependent factors that indirectly influence the outcome of measurements of trust level for the involved organizations. Each domain/application, such as business, manufacturing medical, etc. is affected by both VBE's internal factors (e.g. the minimum wage per hour for all organization within the VBE), as well as the VBE's external factors about environment/market/society considering the VBEs scope both geographical and area wise, for example: (1) some pre-existing regulations or standards (e.g. regional tax subsidies in a given market), (2) an environment's norm and practice (e.g. minimum number of competencies required for each organization to become a VBE member), or (3) the current state of the market/society (e.g. regional availability of raw material or a market consumption capacity of products/services), etc. These factors indirectly influence the trust level assessment by internally influencing the behavior of trust criteria. 
For each VBE, its known factors are identified during the customization of the generic trust management system to the specific domain/application of the VBE. Thus, the main source of data for the known factors is the VBE administration itself that knows about both its internal and external environments. The data about known factors should also be kept up-to-date by the VBE administration.

Intermediate factors: represent the factors that play the intermediary role in relating known factors to the trust criteria. In principle, both trust criteria and known factors do influence each other. Their influences are twofold, consisting of the: causal influences and impact influences. However, these influences are not direct, rather through some intermediate factors. By applying the HICI approach (Msanjila and Afsarmanesh 2007c) the analysis of causal influences among the trust criteria and known factors can be performed and represented diagrammatically in a so called causal diagram. Based on the results of causal analysis, these influence relations are used for derivation of mathematical equations that formally relate the trust criteria and known factors through specific intermediate factors. These equations are further used to calculate the values for each intermediate factor in relation to every organization, thus acting as partial trust level assessment means for the organization. Therefore, unlike the trust criteria and known factors for which the data is respectively assigned by the organization and the VBE administration, intermediate factors must be calculated through these equations. Namely, if needed, the only way that the value of an intermediate factor can be improved is either through the changes in the values of the organizational trust criteria, or changes in the known factors decided internal to the VBE, since these are the only controllable factors that influence it. For example, consider the intermediate factor "organizational expenditure" which is influenced by the two trust criteria of: size (from structural perspective) of an organization - number of employees, and the operational costs (from economical perspective), as well as by the known factor: minimum wage of employees acceptable at the VBE. Changing the expenditure of an organization can be achieved by changing the values of the three above stated elements.

Trust level: Refers to the intensity level of trust for a trustee in a trust relationship, based on the assessment of values for a set of necessary trust criteria. Clearly enough, the criteria for the trust level assessment of organizations are varied and wide in spectrum depending on the purpose (e.g. depending on the requirements, the perspective, and the objective of trust establishment). When trust level is assessed for a certain specific purpose, such as for inviting a member to a VO, and the assessment is based on specific trust criteria for that the purpose, we call the results, specific trustworthiness of the trustee.

Trust relationship: A relationship is a state of connectedness among people or organizations or is a state involving mutual dealing among parties. Trust relationship refers to the state of connectedness between a trustor and a trustee whose intensity is characterized and based on the fact-based assessment of trust level.

\section{Research questions}

The importance of trust relationships among collaborating or cooperating organizations is addressed in Section "Importance of establishing trust relationships among organizations". In order to realize inter-organizational trust in VBEs and thus benefit from these advantages a number of open research questions must be properly addressed. The following three research questions are addressed in this article:

1. Can trustworthiness (trust level) of an organization be measured? How complex is trustworthiness? Does it have a quantitative value, and if so, what is the metric? Furthermore, is it one number or a set of numbers? If not quantitative, then is it a qualitative value, such as good/bad, high/low?

In Msanjila and Afsarmanesh (2007a), we presented an approach for measuring trust level of organizations in terms of values of a set of trust-related criteria. We argued that trustworthiness is complex and can neither be measured with a single value nor interpreted with a single metric. The levels upon which the data about certain trust criteria in an organization meet the specified ratings represent its trust level. Our suggested approach is based on the use of mathematical equations in designing mechanisms for assessing trust level of organizations. The mathematical equations are formulated applying the results of analysis of causal influences among trust criteria, known factors, and intermediate factors. The derivation of these equations is beyond the scope of this paper but the topic is properly addressed in Msanjila and Afsarmanesh (2007a). In brief the mechanisms developed for TrustMan system implement three forms of equations. The first form of equation is applied to calculate the final comparative scores of the trust level for organizations. This equation is represented as the average of weighted scores for all trust perspectives achieved by the organization (Eq. 1). In all the three equations below $\boldsymbol{T L}$ represents trust level, $\boldsymbol{S}$ represents score, perrepresents trust perspective, IF represents intermediate factor, $\boldsymbol{W}$ represents weight, and Avg represents average

$$
\begin{aligned}
T L= & A v g\left[\left(W_{T e c h} * S_{T e c h}\right),\left(W_{S o c} * S_{S o c}\right),\left(W_{S t r} * S_{S t r}\right),\right. \\
& \left.\left(W_{\text {Man }} * S_{\text {Man }}\right),\left(W_{E c o} * S_{E c o}\right)\right]
\end{aligned}
$$

The score for each trust perspective is calculated as weighted average of score for all intermediate factors as shown in Eq. 2 which represents the second form.

$S_{p e r}=\frac{1}{n} \sum_{i}^{n} W_{I F_{i}} * S_{I F_{i}}$ 
The score for intermediate factors is calculated as a function of trust criteria and known factors as shown in Eq. 3 which represents the third form.

$$
\begin{array}{r}
S_{I F}=f \text { [trust_criteria, } \\
0<W_{i}<1, \text { and } \sum_{\forall i} W_{i}=1
\end{array}
$$

2. Does every organization have the same objectives and perspectives for establishing trust relationship with others?

In VBEs, trust must be thoroughly characterized to ease the understanding about the motivations from which organizations prefer to establish trust relationships with others. Antecedents and importance of trust relationships among member organizations must also be addressed. This paper addresses this question.

3. How can establishment of trust among organizations in $V B E$ be achieved and enhanced?

This paper addresses this question by proposing a framework for establishing and promoting trust relationships among organizations in VBEs.

\section{Establishing trust relationships}

In this section we address the establishment of trust relationships among organizations in VBEs. We first present some existing related approaches.

\section{Existing approaches for establishing trust relationship}

Several approaches have been used to establish trust relationships between different actors in various types of environments. These approaches have been used for the establishment of trust relationships either between actors in a specific domain (e.g. in health service provision), or between entities in a specific technology (e.g. agent technologies). The following approaches-namely role-based, reputationbased, interaction-based, and risk-based approaches-used here for exemplification are designed to be applied in either a specific environment or to address specific application cases. Thus, they cannot be directly used when establishing trust relationships between organizations. However, they do have some relevance for the approaches needed to establish trust relationships between organizations in VBEs, as addressed below.

\section{Role based approach}

Role-based trust relationships are established in order to facilitate the adoption of responsibilities related to the roles of organizations in collaborative networks. This approach is mainly used for the establishment of trust relationships between systems representing organizations, which use either multi-agent systems or peer-to-peer interactions in Internetbased relationships (Huynh et al. 2004). Each peer, node or agent represents a single organization in the dynamic community which interacts through the Internet. The approach was developed as a solution to the trust relationship problems in decentralized and dynamic working environments (Field and Hoffner 2003). This approach dictates that an organization cannot take more than one role and that it is trusted only for a specific known role. The approach can be used to create trust in member organizations towards the VBE administrator. Therefore, the VBE administrator is entrusted with the VBE-related administrative tasks.

\section{Reputation based approach}

At the individual level, reputation is an overall quality or character as perceived or judged by people within a community. There are two possible sources of an organization's reputation-related information that is to be accessed when establishing a trust relationship with others. The first is the Witness reputation, which refers to the reputation-related information that is collected by the trustor, or the trustor's associated organizations (friends) (Huynh et al. 2004). In this case, the trustor organization or its associated organizations must observe the necessary character of the trustee organization. In VBEs, where organizations collaborate virtually, the adaptation of this approach is hardly feasible. The second reputation is the Certified reputation, which refers to the reputation-related information that is collected by the trustee organizations and made available to the trustor organization. The trustee organization can provide information such as a detailed organization profile to the trustor organization in order to enhance its trust level. The trustee organization can also request its friend/authorized organizations to provide positive information (e.g. accreditation document) to the trustor organization in order to enhance its trust level. The main problem of this approach is that there is high risk of user-biased information, which endangers the success of the resulting trust relationships. The validation of such information is also difficult since, in practice, bad reputations are usually hidden.

\section{Interaction based approach}

In practice, past experiences resulting from direct interactions between organizations enhance the chance of successfully establishing trust relationships. Nevertheless, member organizations sometimes need to collaborate with other entirely unfamiliar VBE member organizations. Consequently, this approach cannot be applied to every case in VBEs. 


\section{Consumer-opinion based approach}

This approach is used to establish trust relationships between customers and suppliers/producers. It is based on the opinions, ranking or comments provided by customers on the quality of the products/services that they purchase/use. While buying/using products/services the customers are typically requested by a website to comment (rank) the quality of the same product/service (e.g. a television or a hotel room, etc.) from a number of producers/providers. The comments (ranks) are then organized in scorecard format by that site. The results from the scorecard are then made available to future customers for smoothing the creation of trust to certain producers/providers. This approach is applicable to online businesses in most cases, which means that proving the data validity might be difficult.

\section{Risk based approach}

This approach focuses on reducing the potential risks that may occur during collaboration. As such, the confidence that organizations have of the limited number of potential risks enables them to trust each other. In practice, however, risks relate to unexpected results and as such are unpredictable. Therefore, it is almost impossible to avoid risks. This is difficult even in VBEs that use virtual collaboration and cooperation as the key approach for collaboration. This topic is further addressed in Section "Risks in VBEs versus trust relationships between organizations".

FETR: A framework to establish trust relationships among organizations in VBEs

A framework is a conceptual structure used to approach and solve a complex issue. It is usually used to outline possible courses of action and to provide a preferred approach for each of these actions, in order to achieve an optimal collective outcome. Therefore, frameworks present "re-usable designs and guidelines" that can be applied to assist their users in undertaking certain actions related to the issue of the framework in different cases. Furthermore, frameworks must address all of the actions necessary to accomplish the supported processes and generate the solution.

Consideration for a large number of specific fundamental aspects is necessary when addressing trust between organizations in VBEs. We characterize inter-organizational trust as a multi-objective, multi-perspective, and multi-criteria subject. It is a challenging task to comprehensively cover all of these specific fundamental aspects of inter-organizational trust and thus use them to facilitate the establishment of trust relationships between organizations. A single specialized approach, such as any of those addressed in Section "Existing approaches for establishing trust relationship", cannot adequately cover all of the fundamental aspects of trust that need to be considered while establishing trust relationships between organizations in VBEs. Accordingly, a generic but comprehensive and structured framework must be designed that will support the realization of interorganizational trust relationships in VBEs.

In order to effectively establish trust relationships between organizations in VBEs for different domains and application cases, a framework will be developed that will guide the processes and actions to be taken. We propose a "two phase" Framework for Establishing Trust Relationships (FETR) between organizations. The first phase- - "relationship characterization and preparation"-consists of three steps: the assessment of organizations' levels of trust, the validation of trust level results, and the presentation and interpretation of trust levels. The second phase,-- "launching trust relationship"- consists of one step, namely the creation of trust between organizations. Figure 1 illustrates the proposed framework. This framework is discussed in further detail below, with a description of each phase and the respective steps.

\section{Phase I: relationship characterization and preparation}

A number of specific steps must be taken in order to characterize the planned relationships and prepare organizations on a number of essential aspects in establishing their goal-oriented trust relationships. This phase constitutes three specific steps that aim to guide both the trustor and trustee organizations when preparing themselves to trust other organizations for the purpose of the intended collaboration. It involves guiding the trustor organization in assessing their respective trustee organizations' levels of trust, validating the achieved trust level assessment results, and interpreting and presenting those results to the trustee organizations. We have characterized this phase into three specific steps: (1) the assessment of organizations' levels of trust, (2) the validation of trust level results, and (3) the presentation of trust level results. These three specific steps constitute Phase I of the FETR framework, as discussed below.

\section{Step 1: Assessment of trust level of organizations}

An assessment of levels of trust is one of the fundamental steps for establishing trust relationships between organizations. The aim of this step is to ensure that the organizations involved have acceptable trust levels and that their trust levels are correctly balanced. In VBEs, the assessment of organizations' levels of trust is performed for three purposes, namely for ensuring that (1) the trust of a VBE membership applicant meets the minimum trust level acceptable in the VBE (the base trust level); (2) that all of the member organizations conform to the base trust level specified in the VBE; 


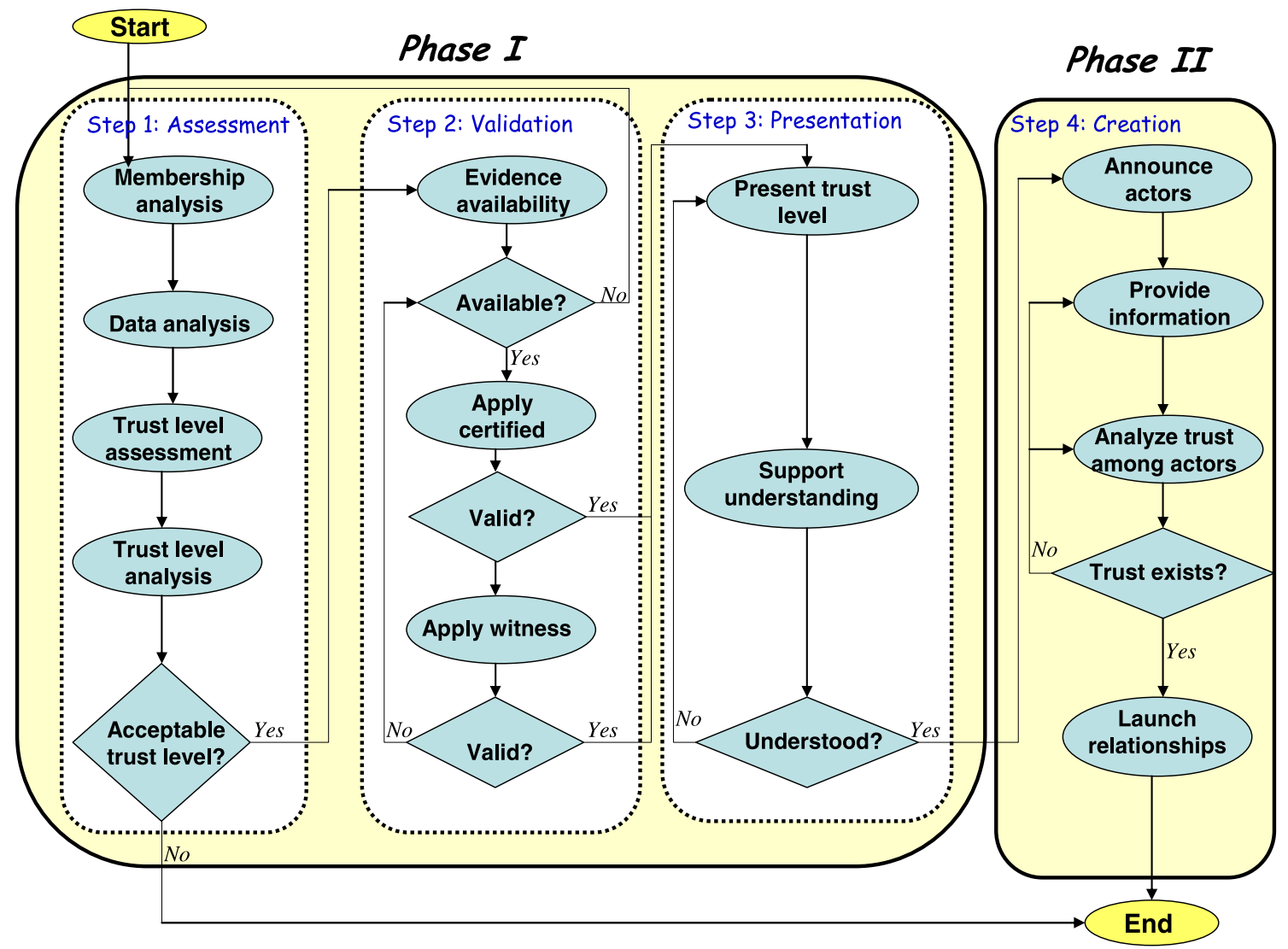

Fig. 1 A framework for establishing trust relationships among organizations

and (3) that the specified trustworthiness for an objective is met by all of the partners involved (as addressed in Msanjila and Afsarmanesh (2007a)). Depending on the purpose of the relationship being established, one of these three trust level assessments will be performed.

In our approach for assessing organizations' levels of trust, we suggest the use of multi-criteria. In fact, in the proposed approach, a number of complex and heterogeneous aspects of inter-organizational trust have been characterized, modelled and applied to mechanisms for assessing trust level of organizations. Thus, we have observed that the organizations' levels of trust can neither be measured with a single trust criterion, nor be interpreted with a single metric (as addressed in Msanjila and Afsarmanesh (2007c)). Furthermore, organizations' levels of trust are not absolute values that can be applied in every case, rather values that can be used for the purpose of comparison. Trust level comparativeness is valid for a given rating, the participating organizations, and the set of trust criteria preferred by the trustor organization.

As described in Msanjila and Afsarmanesh (2007a), the mechanisms for assessing organizations' levels of trust apply a set of base trust criteria that are preferred by a given VBE environment. These assessment mechanisms are developed with the aid mathematical equations as introduced in section
"Research questions". The mathematical equations are formulated using the results of an analysis of causal influences between trust criteria. As such, these equations provide formal representations of the inter-relations (mostly, causal influences) between trust criteria. Therefore, the assessment of organizations' levels of trust can thus be stated as using formal mechanisms. Consequently, the rational (formal) reasoning of the resulting levels of trust is supported through mathematical equations in our approach. The subject of formulating mathematical equations relating the causal influences between trust criteria is addressed in detail in Msanjila and Afsarmanesh (2007a). That paper also discusses the generalization of these equations and the use of such to design mechanisms for assessing organizations' levels of trust. In doing so, we address how the comparative trust level of an organization can be calculated and thus how trustee organizations' levels of trust can be regarded as formal results and supported with certain formal reasoning mechanisms.

However, the processes related to assessing the trust levels of organizations as addressed in our approach are too complex to perform manually. In Msanjila and Afsarmanesh (2007e, 2008) we have presented the specifications of the Trust Management (TrustMan) system, which has been developed as a means to provide services that automate the 
processes related to the management of inter-organizational trust within VBEs. The assessment of organizations' levels of trust is one of the fundamental services provided by the TrustMan system. The design and implementation aspects of the TrustMan system are also further addressed in Msanjila and Afsarmanesh (2008).

Step 2: Validations of resulted trust level of organizations

In order to assess organizations' levels of trust, in our approach we propose the use of data relating to the performance of organizations as the fundamental input. The performance data (referred to here as trust-related data) is expressed in terms of values of trust criteria. In Msanjila and Afsarmanesh (2007c) we presented the impact analysis approach, as part of the HICI approach, which is used to analyze the relations between trust criteria and organizational performance. In addition to expressing the performance of organizations in terms of values of trust criteria, the sources of the data must be validated.

A priori to assessing levels of trust, the organizational trust-related data is made available to the VBE. Thus, the evidence supporting the validity of the data provided by the organizations is collected in advance and presented to trustor organizations if and when required. Therefore, the trustrelated data used for each organization is validated a priori to confirming the resulting levels of trust. By validating this trust-related data, the resulting organizational trust levels will also be validated. In Section "Types of validity evidences for trust-related data" some sources of evidence are suggested which can assure/support the validity of trust-related data that is made available in the VBE by each organization.

Therefore, "step 2 of phase I" focuses on validating the trust related data applied for the assessment of trust level of each involved organization (Fig. 1). If the validity evidences of data for certain involved organizations are missing or inadequate then its computed trust level is disqualified.

\section{Step 3: Presentation and interpretation of trust levels}

As previously discussed, our approach for the assessment of trust levels is based on a set of trust criteria that is specified in the VBE. This set of trust criteria depends on the type of trust level assessment, namely either for "base trust level" or "specific trustworthiness". The set of base trust criteria is selected by the VBE administrator, and the set of specific trust criteria is selected by the each trustor organization. The trust level results are expressed in terms of comparative values of the applied trust criteria. Understanding and interpreting these trust levels accurately in terms of the values of a set of trust criteria, is a complex and difficult task for most decision-makers (such as managers and directors) who are not experts in trust or mathematics.
A priori to helping them understand the resulting trust levels of organizations, these actors must be assisted in their understanding of the base concepts of trust, as perceived in the specific VBE. In Msanjila and Afsarmanesh (2007b) we presented an ontology-based trust model which can be used to achieve the required level of understanding (Msanjila and Afsarmanesh 2007b). In Afsarmanesh and Ermilova (2007), the authors detail the use of ontology for enhancing the knowledge of actors in VBEs on different aspects, and propose the Ontology Discovery and Management System (ODMS) for this aim. The provision of trustrelated concepts in ontological format is also supported by the ODMS.

Furthermore, trust levels must be presented in a format which is as understandable as possible. However, the assistance of trust experts in specific domains or environments to interpret the levels of trust is helpful to decision makers. In our approach we propose providing support to assist decision-makers and other users in interpreting and representing levels of trust in an understandable format, such as qualitative values. Therefore, we have suggested a qualitative format to represent the comparative trust levels in five ratings, namely strongly less trustworthy, less trustworthy, average trustworthy, more trustworthy, and strongly more trustworthy. Figure 2 shows the relations among these qualitative trust levels.

As described in section "Research question", mechanisms proposed for assessing trust level of organizations are based on mathematical equations. Thus the resulted values from the computation of the trust level of organizations are numbers which are here referred to as trust level scores. These scores are comparative values ranging between 0 and 5 . The VBE administrator decides, during the customization of the TrustMan system, the specific sub-ranges to be represented in terms of qualitative values as indicated by the trust-meter.

\section{Phase II: launching trust relationship}

When trust between the participating organizations is successfully created, trust relationships between them can be initiated. Various approaches used for initiating established trust relationships are in practice, but the most popular one is contracting. At this stage, organizations trust each other and thus guarantee each other, by means of a contract, that they can now start collaborating for the current common goals. The creation of trust and the launch of trust relationships between the participating organizations constitute the main objectives of Phase II, and its single step- the Step 4-as further described below.

There are two kinds of trust relationships that can be established between organizations, namely short-term trust relationships and long-term trust relationships. Short-term trust relationships are established to facilitate collaborations between organizations that will exist for a relatively short 
Fig. 2 Trust-meter for representing trust levels among organizations
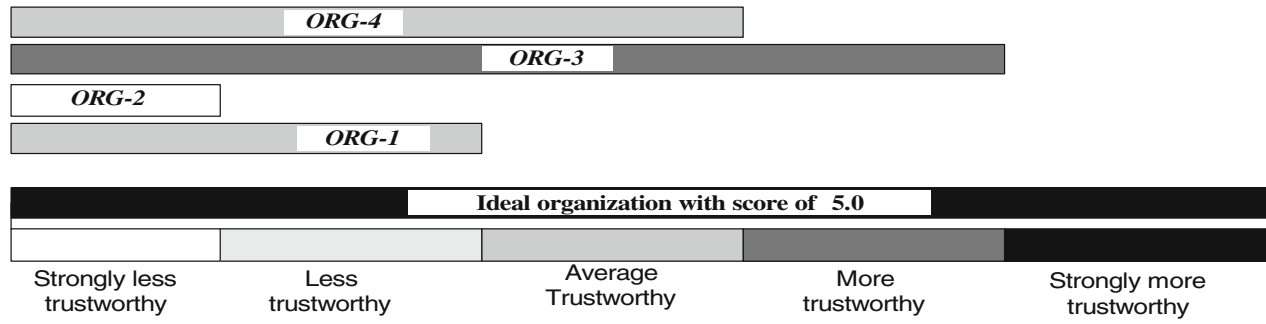

period of time, e.g. collaborations in VOs. Long-term trust relationships are established to facilitate collaboration between organizations that will exist for a relatively long period of time, e.g. cooperation in VBEs.

Step 4: Creation of trust among organizations and initiation of their trust relationships

Once the trust level results are validated and confirmed, the organizations with acceptable levels of trust as rated by the trustor can be identified. In order to create trust between the participating organizations, each one must be helped to understand the trustworthiness of other organizations in order to encourage the establishment of trust relationships with them. Consequently, each organization needs sufficient and convincing information to assist its trust and understanding of other organizations. However, the perceptions of trust and thus the preferred trust perspectives may not be uniform and can vary among the participating organizations. The challenging question is which information should be provided to each specific organization to meet both its perception and preference on trust, and how detailed should this information be?

In our approach, the creation of trust of the trustor organization to the trustee organization is based on the performance of the respective trustee organization. Based on its preferred trust perspectives, the trustor organization will be provided with as detailed information as is sufficient to create the required trust. The details of the information provided will also differ according to the following five aspects:

- Who: Collaborations among organizations in VBE are characterized as goal-oriented. Thus, the trust relationships that will be established using our suggested framework will also be goal-oriented. Organizations will trust others on the basis of the role that the latter will play a role in helping to achieve the goal of the relationship. For example, in virtual organizations the roles that can be assumed are coordinator and partner. Each role might need different kinds of information to enable the trustor organization to trust the trustee organization with this specific role.

- When: In our proposed approach for assessing levels of trust and creating trust in an organization requires the application of an organization's past performance data as the fundamental input. The word "past" here represents a subjective nature to the previous time. It is not clear how far into the past the performance data will need to cover to be enough for the trustor organizations. The preferred time of the collection of information and of the provision to the trustor will differ between the trustor organizations and the trustee organizations.

- What: This refers to the content of the information that will be provided to each organization that is participating in the trust relationship. It is not easier to define in advance the specific types and content of information that each organization might need in every trust relationship. The type and content of information will depend on how the respective organization's trust and trust perspective are perceived.

- How: The validity of the information will be influenced by both its sources and the applied mechanisms/tools for collection and provision. When the sources of information are highly trustworthy, the value of the information as far as trust is concerned will also be high. Furthermore, the mechanisms used for collecting and providing the information might also influence the decision made by specific trustor organizations on its suitability. Thus, both the sources of information and the mechanisms used to collect and provide this information will influence the decision made by the organizations on its use.

- Why: The information that is provided to specific organizations will also depend on the reason why it is requested. Here, this refers to the main trust objective and related sub-objectives for establishing the trust relationship.

\section{Types of validity evidences for trust-related data}

Information made available to a VBE by an organization in order to assess its levels of trust must be supported by difference types of validity evidence. This section addresses evidences that can be used by organizations to assure the validity of their trust-related data.

Witness evidence

These evidences constitute a certain form of documentation generated by third parties that, even though they provide 
some proof of accuracy for their respective information, they cannot be considered as official and authorized proofs. Such witnessed evidences may include information obtained from: (1) Public channels, (e.g. the magazines, newspapers) and (2) Private channels, (e.g. recommendations).

Although these types of evidence are not as strong as the authorized evidence, when authorized evidence is lacking and depending on the source of the evidence, they can provide some assurance of the validity of the provided information. Clearly, the weight of this validity increases if the channels used (the news sources or the person providing the recommendation) are publicly recognized. For example, reputable news media put extra effort into discovering the truth about the story they report, although their report can only focus on certain aspects of the story and it does not guarantee the provision of comprehensive coverage. Similarly, a letter of recommendation from A about B only shows a limited number of B's qualifications, as they are known to party A.

\section{Authorized certified evidence}

The validity of information in this category is based on welldefined and agreed standards that the information must meet. The validation is usually performed by authorized organizations. In light of the need illustrated in this article for the validation of the trust-related data of organizations, we suggest the following five sources of evidences:

- Accreditation: Accreditation is defined as an independent act of granting recognition to an organization, as a proof that the respective organization meets and maintains the specified standards. In the health sector, for example, accreditation is an independent external review process that assesses the quality of healthcare services in order to encourage better performance and assure the public of the quality of the services provided by the organizations (Lichiello and Turnock 2002). Accreditation standards are traditionally set at what are considered to be the minimum achievable and allowed levels. Accreditation is traditionally practiced for quality, cost, andbusiness processes.

- Financial rating: Financial rating (credit rate) is a published ranking that is based on a detailed financial analysis, which is performed by a credit bureau and which focuses on the financial history of an organization andin particular-its ability to meet payment obligations. VBE member organizations must validate their financial record and have it approved by authorized organizations that are involved in the analysis. Approval is thus sought for aspects includingcredit score, in-depth financials, solvency, profitability ratios, bankruptcy prediction, etc.
- Patent: A patent is a set of exclusive rights granted by an authorized party to an organization for a fixed period of time in exchange for the regulated or public disclosure of a certain device, method, process or composition of matter (substance) (known as an invention) which is new, inventive, and industrially applicable. Patents granted for organizations could be used as evidence for performance data.

- License: License is an official or legal permission to do or own a specific item. A license can be a document, plate, or tag that is issued as proof of official or legal permission to own something or carry out an activity (i.e. a business license). In legal disciplines, a license is an actual permission to an act in a way that would be otherwise unlawful. The issue of a license with intellectual property rights, such as a copyright or trademark, is proof of permission to use, reproduce, or create an instance of the licensed work. License can also be used to prove the validity information provided by an organization.

- Certificate and awards: A certificate is an official document affirming the fact of a certain achievement. For example, a business registration certificate testifies to basic facts regarding the formulation and formal existence of an organization. In computing and in particular computer security and cryptography, the word certificate generally refers to a digital identity certificate, also known as a public key certificate. An award is something given to a person or organization to recognize excellence in a certain field. Such proof can also be used as a means to validate the information provided by an organization.

\section{Promoting trust relationships among organizations}

There are several complications that member organizations might face when cooperating with each other. These complexities can also increase the difficulty of establishing trust relationships between organizations. Among others, these complications include social, economical, technological, and behavioral related complexities. However, once an organization is confident that there are potential benefits related to its involvement in the VBE, there is a high chance of successfully establishing trust relationship with other organizations. Promoting high trust level of organizations will ease the process of establishing their inter-organizational trust relationships. In this article we suggest four approaches for promoting trust level of organizations which in turn enhances the chance involvement or participation in trust relationships:

\section{- Committed participation in VOs:}

Every VO does have requirements such as resources, competencies, etc., that each partner must possess. When 
an organization manages to participate in many VOs it indicates that it has the capabilities and it meets the required trust level for the collaboration. The participations in VOs enable it to improve its performance records, e.g. by clearing their bad image, if any, which in turn enhances its trust level.

- Higher level of VBE membership:

A VBE is managed through the agreed working and operating principles. There are certain rules and requirements therefore that a VBE member organization must meet and comply with in order to receive membership. Three membership levels are defined in the VBE (Afsarmanesh and Camarinha-Matos 2005), namely fully active, loosely associated, and external level (very loose). The more committed rules are involved, the higher the membership level and the higher the membership level, the higher the level of trust will be. Consequently, organizations must be encouraged to achieve the highest level of membership.

- A VBE's market performance and branding (market credibility):

Branding and marketing carried out by a member organization in external markets not only increases its levels of trust, but also the reputation of the VBE and the opportunities for brokering. Organizations that perform better in the market, (e.g. bring many opportunities to the VBE), have high chances of successfully establishing trust relationships with others.

- Point accumulation and rewarding:

This approach requires the development of mechanisms and tools that will assess achievements that in turn form the basis for either awarding points for productivity, or deducing points for failures. The points are accumulated and later used as a means to gain a quick indication of the trustworthiness of organizations.

\section{Risks in VBEs versus trust relationships between organizations}

Risk refers to a potential negative impact on an asset or value that may arise from a present process or a future event. Generally, risk is related to potential losses resulting from uncertain transactions. Traditionally, risks are assessed on the basis of the probability of their occurrence. In this section we address potential risks that can arise in VBEs and their possible impacts on inter-organizational trust relationships.

Risks that can occur during cooperation in VBEs

Different types of risks may arise during the process of collaboration between VBE member organizations. Below are seven types of risks that may be addressed in order to reduce the severity of their impact on inter-organizational trust relationships in the VBE.

- Strategic risks: Several different strategic risks may be associated with operating in different types of business or industry domains. These include risks arising from acquiring business opportunities, changing customers, changes in customers' demands, changes in operating environments, and emerging innovative results from research and developments. Organizational strategies must be flexible enough to accommodate the changes. Rigid strategies can result in risks, such as the failure of an organization to properly integrate and collaborate with others as a result of unacceptable or outdated strategies (Jøsang and Lo Presti 2004).

- Operational risks: Operational risks may exist as a result of direct or indirect loss that has been caused by inadequate or failed internal processes, employees, or systems. An organization's failure to achieve the agreed results as a result of internal problems endangers the entire consortium and thus the potential to achieve the common goals. Therefore, operational risks that may arise for both organizations and the consortium must be properly addressed.

- Legal issues and cross border risks: These are risks that may exist due to changes of government or local authorities, rules, regulations and laws. Usually business organizations are not involved in proposition of legal issues and thus they have limited influence on their formulations. In a VBE, however, organizations might belong to different legal systems and even from different countries. Changes in legally related issues in a country where some member organizations are located might create risks for their cooperation with others.

- Compliance risks: Compliance risks are those associated with the need to comply with laws, regulations or norms. They also apply to the need to act in a manner that is expected by other organizations and customers, for example by avoiding opportunistic behaviour. Since VBEs are not closed border, various standards might exist in different markets. Collaboration between organizations operating with different standards in such markets might face the risk of failure to comply. In some cases these standards might even contradict each other. Compliance risks are also associated with the violation of, or non-conformance with, laws, regulations, norms, and ethical standards. Assuring compliance becomes more difficult to prove with current information and communication technologies (ICTs) and virtual collaborations.

- Financial risks: These are the risks associated with the financial aspects of the collaboration. They refer to the chance that an actual investment's return is lower than 
expected, which includes the possibility of losing some or all of the original investment due to issues such as failure to pay by customers and opportunism by partners in the collaboration consortium. Financial risks are measured using the returns for a specific investment. There are various types of financial risks relating to areas such as credit, liquidity, transactions, interest rate and foreign exchange.

- Reputation risks: Reputation risk is related to an organization's image and instability as a result of negative opinions, either from other member organizations in the VBE, or from the public. These affect an organization's ability to establish new trust relationships with other organizations, or to continue with existing trust relationships. This risk may expose an organization to litigation, financial loss, or loss of customers. Reputation risk exposure must be dealt with throughout the organization, and requires exercising caution in dealing with customers and the community.

- Technology risks: Current risks surrounding ICTs, such as network failure, lack of resources and skills, hacking and viruses have the potential of a greater negative impact on an organization than ever before, since collaboration and cooperation are both facilitated by computer networks. Several risks exist regarding the collaboration, to which an organization must be prepared to quickly respond. These involve security, privacy, information access, applied technologies complexity related risks, and so on.

Risks avoidance versus commitment to trust relationships

In traditional business investment, it is generally the case that the greater the risk a person takes, the higher the return that he/she will expect to receive, and the less the risk will entail a lower return. Tradeoffs concerning organizations in relation to risks are about the values that will be received or obtained once a specific risk has been accepted. However, cooperation between organizations in VBEs does not provide a direct return value. The economical benefits of cooperation between member organizations include an increase in their chance of acquiring better and more opportunities and involvement in responses to opportunities brokered with others.

In practice, trust and risks are inversely related - when one increases there is a high chance that the other will decrease. Therefore, if risks existing in a certain environment increase, organizations operating in this environment will feel at risk and unable to rely on the collaboration of others. Similarly, if organizations trust each other to a great degree they will feel that risks are unlikely to arise during the course of collaboration.
Considering the style of collaboration in VBEs (i.e. virtual cooperation), organizations may interact with others without knowing them physically, thus enhancing fears about potential risks. A number of risks that can exist in VBEs have been discussed in Section "Risks that can occur during cooperation in VBEs". One strategy that organizations can assume as a means to avoid risks associated with collaboration is either not to commit to trust relationships or to resist establishing such trust relationships by being reluctant in creating trust towards others. Such a strategy can in fact cause problems with respect to sharing resources, knowledge, and competency, as well as exchanging the information that is necessary for facilitating the collaboration.

Cooperation is the most potential style for long-term and strategic co-working among organization. This co-working style among organizations been demonstrated to be suitable for member organizations within VBEs (Afsarmanesh and Camarinha-Matos 2005). Trust and trust relationships have proven to be fundamental facilitators that ease cooperation between organizations in VBEs and their collaboration in VOs. A challenging issue for VBE administrators, however, is how to convince organizations to establish and commit to trust relationships despite the existing risks. In the VBE, member organizations are encouraged to trust others in order to smoothen their collaboration through the following strategies:

- Enhancing the sense of togetherness and safe feelings among member organizations in the VBE by promoting the culture of sharing day to day information, useful knowledge, etc., through the common storage and retrieve portal called "bag of assets" (Afsarmanesh et al. 2008).

- Defining and applying a comprehensive set of "working and sharing" principles that can also provides guidelines on how to share any kind of loss among organizations due to emerged risks during the collaboration (Romero et al. 2008).

- Define and encourage use of proper value system in the VBE that will also provide a set of performance indicators for measuring performance of organizations, which in turn provide data to be used as input to the computation of the trust level of organizations.

- Define rewarding strategies, and build reward mechanisms that encourage good behavior and high achievement in collaborative activities.

\section{Conclusion}

In this paper we have presented the FETR: A Framework for Establishing Trust Relationships among organizations. 
The presented framework which constitutes "two phases and four steps" applies four main concepts, namely: assessing trust level of organizations, validating trust levels, support for understanding and presenting trust levels, and creating trust among organizations.

Collaborative Network $(\mathrm{CN})$ is a new discipline and thus a number of its related areas need new and innovative solutions. Trust among organizations in VBEs-a form of $\mathrm{CN}$ that acts as the breeding environment for VOs-is one area directly in need of addressing trust issues. For such cluster of organizations the study of related (fact based) inter-organizational trust, its measurement, and the establishment of trust relationships among VBE member organizations is challenging.

FETR framework incorporates the concept of collaboration among organizations. It addresses a number of steps which must be taken while establishing their trust relationships. In fact each step of FETR addresses specific fundamental aspects of inter-organizational trust, which are not properly covered by the traditional approaches.

The FETR framework aims at providing a potential candidate for facilitating the process of establishing trust relationships among organizations. It applies the concept of rational trust, specifically in step 1 , which addresses the assessment of trust level of involved organizations. However, in practice, the rational (fact based-objective) trust and the subjective trust (related to reputation of trustee and opinion of others) complement each other. For instance, when the value for a large number of trust related criteria for an organization needed for the computation of its rational trust level is missing, incomplete or not up-to-date the subjective approach to trust can be applied to cover the missing elements. Thus the interlinking between the two aspects must be addressed to enhance the applicability of FETR framework for all potential cases. This is an open research challenge to be reported in our future publications.

In this paper we have addressed specifically the subject of "establishment of trust relationships among organizations". We have also presented the antecedents and importance of trust relationships among organizations involved in CNs. The fundamental validity evidences of the information needed for assessing the trust level of organizations, which in turn constitutes the base for establishment of trust relationships, are presented. Moreover, risks that can emerge during the collaboration as well as during the operation stage of the VBEs are also addressed.

Acknowledgements This work was supported in part by the ECOLEAD project funded by the European Commission. The authors thank for contributions from partners in the ECOLEAD consortium.

Open Access This article is distributed under the terms of the Creative Commons Attribution Noncommercial License which permits any noncommercial use, distribution, and reproduction in any medium, provided the original author(s) and source are credited.

\section{References}

Afsarmanesh, H., \& Camarinha-Matos, L. (2005). A framework for management of virtual organization breeding environments. In Collaborative Networks and their Breeding Environments (pp. 3549). Springer.

Afsarmanesh, H., \& Ermilova, E. (2007). Ontology management for VO breeding environments. In Proceedings of 9th International Conference on the Modern Information Technology in the Innovation Processes of the Industrial Enterprises. Italy, pp. 124137.

Afsarmanesh, H., Msanjila, S. S., Ermilova, E., Wiesner, S., Woelfel, W., \& Seifert, M. (2008). VBE management system. In Methods and tools for collaborative networked organizations (pp. 119-154). New York: Springer. ISBN: 978-0-387-79423-5.

Camarinha-Matos, L., \& Afsarmanesh, H. (2006). Collaborative Networks: Value creation in a knowledge society. In Knowledge enterprise: Intelligent strategies in product design, manufacturing and management. Proceedings of PROLAMAT 2006, IFIP Int. Conf. On Knowledge Enterprise - New Challenges (pp. 26-40). Springer, Shanghai, China, Jun 2006. Springer.

Cosimano, T. F. (2004). Financial institutions and trustworthy behavior in business transactions. Journal of Business Ethics, 52, 179-188. doi:10.1023/B:BUSI.0000035919.45227.c3.

Gambetta, D. (1988). Trust: Making and breaking cooperative relations. Basil Blackwell.

Grandison, T., \& Sloman, M. (2000). A survey of trust in Internet applications. In IEEE communications survey and tutorials. Fourth quarter, pp. 2-16.

Field, S., \& Hoffner, Y. (2003). Web services and matchmaking. International Journal of Networking and Virtual Organizations, 2(1), 1632.

Huynh, D., Jennings, N. R., \& Shadbolt, N. R. (2004). Developing an integrated trust and reputation model for open maulit-agent system. In Proceedings of 7th workshop on Trust, Privacy, Deception and Fraud in Agent Societies (pp. 65-74). USA.

Jøsang, A., \& Lo Presti, S. (2004). Analysing the relationship between risk and trust. In Proceedings of Trust Management Second International Conference (pp. 135-145). Oxford, UK.

Lichiello, P. \& Turnock B. J. (2002). Guidebook for Performance measurement. Turning point - Collaboration for a new century in public health.

Mayer, R. C., Davis, J. H., Schoorman, F. D. (1995). An integrated model of organizational trust. Academy of Management Review, 20(3), 709-734. doi:10.2307/258792.

Morgan, R. M., \& Hunt, A. D. (1994). The commitment-trust theory of relationship marketing. Journal of Marketing, 58(3), 20-38. doi:10. 2307/1252308.

Msanjila, S. S., \& Afsarmanesh, H. (2007a). Trust Analysis and Assessment in Virtual Organizations Breeding Environments. International Journal of Production Research, 46(5), 1253-1295. ISSN: 00207543.

Msanjila, S. S., \& Afsarmanesh, H. (2007b). Modeling Trust Relationships in Collaborative Networked Organizations. International Journal of Technology Transfer and Commercialisation, Inderscience, 6(1), 40-55. ISSN (Print): 1470-6075.

Msanjila, S. S., \& Afsarmanesh, H. (2007c). HICI: An approach for identifying trust elements-The case of technological perspective in VBEs. In Proceeding of International Conference on vailability, Reliability and Security (ARES-2007) (pp. 757-764). Vienna. April.

Msanjila, S. S., \& Afsarmanesh, H. (2007d). Towards establishing trust relationships among organizations in VBEs. In Establishing foundation of collaborative networks - Proceedings of PRO-VE 2007, IFIP (Vol. 225, pp. 3-14). Springer. 
Msanjila, S. S., \& Afsarmanesh, H. (2007e). Specification of the TrustMan system for assisting management of VBEs. In The Lecture Notes of Computer Science Series, LNCS 4657 (pp. 34-43). Springer.

Msanjila, S. S., \& Afsarmanesh, H. (2008). On architectural design of trustMan system applying HICI analysis results. The case of technological perspective in VBEs. International Journal of Software, 3(4), 17-30. ISSN: 1796-217X.

Mukherjee, A. (2003). A model of trust in online relationship banking. Journal of Bank Marketing, 21(1), 5-15.

Romero, D., Galeano, N., \& Molina, A. (2008). VO breeding environments value systems, business models and governance rules. In Methods and tools for collaborative networked organizations (pp. 69-90). New York: Springer. ISBN: 978-0-387-79423-5.
Rousseau, D. M., Sitkin, S. B., Burt, R. S., \& Camerer, C. (1998). Not so different after all: A cross-discipline view of trust. In Academic management review (Vol. 23, pp. 393-404).

Rtanasingam, P. (2005). Trust in inter-organizational exchanges: A case study in business-to-business electronic commerce. Journal of Decision Support System, 39(3), 525-544. 